\title{
Research on the Issuance Mechanism and Implementation Path of Multi-Body Asset Securitization Products of China Rural Banks
}

\author{
Lingjuan $\mathrm{Xu}^{1}$, Xinyue $\mathrm{Liu}^{1}$, Zhu Huailei ${ }^{2} \&$ Sun Jing $^{3}$ \\ ${ }^{1}$ College of Economics and Management, Nanjing University of Astronautics and Aeronautics, China \\ ${ }^{2}$ Nanjing Pukou Jingfa Country Bank, China \\ ${ }^{2}$ College of Finance, Nanjing Agricultural University, China \\ Correspondence: Lingjuan Xu, College of Economics and Management, Nanjing University of Astronautics and \\ Aeronautics, China. Tel: 86-137-7052-2735. E-mail: linda_xu@ nuaa.edu.cn
}

Funded project: Humanities and Social Sciences Research and Planning Fund of the Ministry of Education (19YJA790098); Social Science Foundation of Jiangsu Province (15EYB007).

Received: December 26, 2019

Accepted: February 25, $2020 \quad$ Online Published: February 27, 2020

doi:10.5539/ijef.v12n3p64

URL: https://doi.org/10.5539/ijef.v12n3p64

\begin{abstract}
Asset securitization can well solve the bottleneck problem of China rural banks in supporting the development of agriculture, rural areas and farmers. However, a single entity will face many constraints on issuing credit asset-backed securitization products due to the small scale, short term and high credit risk of loans of rural banks. Therefore, this paper innovatively designs a credit asset-backed securitization product program jointly issued by a number of rural banks from the three aspects of asset pool construction, transaction structure design and credit enhancement, and demonstrates the feasibility of the program with an example, and the results show that the design scheme of asset securitization products is feasible and effective.
\end{abstract}

Keywords: rural bank, asset-backed securitization, distribution mechanism, implementation path

\section{Introduction}

Asset securitization is an efficient way of financing, which plays an important role in enhancing the financing capabilities of financial institutions, reducing financing costs, and improving competitiveness. After the financial crisis, China's asset securitization pilot was restarted in May 2012. With the continuous development of financial innovation in recent years, the scale of asset securitization products has also increased rapidly. By the end of 2018, the scale of China's issued asset-backed securities reached 4.4 trillion yuan. Although the scale of asset securitization has expanded rapidly in recent years, rural financial institutions have rarely participated. On April 27, 2018, the People's Bank of China, the China Banking Regulatory Commission, the China Securities Regulatory Commission, and the State Administration of Foreign Exchange jointly issued the "Guiding Opinions on Regulating the Asset Management Business of Financial Institutions". The new regulations on asset management serve the real economy and accelerate industrial structure The goal of transformation and upgrading coincides with the original intention of rural financial institutions to support the three rural economy. For a long time, the limited storage capacity of rural banks and the special purpose of serving agriculture, rural areas, and farmers has resulted in low profit margins. At the same time, with the domestic economic downturn, the risk exposure of the banking industry has continued to increase, and the profit growth rate has slowed down rapidly. Internal financing methods of financing and free capital accumulation cannot solve the problem of the credit fund gap of China rural banks. In order to improve the efficiency of the use of stock funds, it is necessary to further advance the credit asset securitization business, and provide solutions for the rural banks in China to revitalize the stock funds and supplement the funding gap.

The issuance of asset-backed securities by banks has a positive effect on the banks themselves in improving liquidity, changing capital structure, reducing credit risk, and improving return on net assets. There are few domestic studies on asset securitization in rural financial institutions. Regarding the issue of asset securitization products to promote the development of agriculture, rural areas and farmers, Haifeng and Shijin (2015) proposed that the use of asset securitization can improve financing efficiency and promote urban economic development. 
Regarding the asset securitization of rural household loans by rural banks, Zhaowei and Rihong (2013) proposed that the issuance of asset securitization products with rural household loans can speed up the financial cycle of rural financial institutions; Jianguo et al. (2017) elaborated the pricing ideas of rural household loan securitization, Lei and Lina (2015) summarized the constraints and countermeasures by studying the asset securitization process of rural financial institutions. At present, there are few studies on the credit asset securitization business of rural banks in China, and they are mainly focused on the policy level. The feasibility study on the asset securitization of rural banks is still blank. To this end, this paper analyzes the unique operating characteristics of rural banks that are different from other commercial banks. From the perspective of the issuance mechanism and implementation path of asset securitization products of rural banks, based on the operating characteristics and dilemmas of rural banks, the bank pool construction, transaction structure design, and credit enhancement in the process of asset securitization of rural banks are targeted. Based on the operating characteristics and dilemmas of rural banks, the bank pool construction, transaction structure design, and credit enhancement in the process of asset securitization of rural banks are targeted. We propose specific plans for small-scale entities to issue asset securitization products.

\section{Issuance Mechanism}

\subsection{Current Status of Asset Securitization in Rural Financial Institutions}

Since the resumption of credit asset securitization in 2012, the scale of credit asset securitization has been continuously expanding, especially since 2015. In 2018, the inter-bank market issued 155 asset securitization products, with a total issue size of 9318.35 billion yuan, an increase of $55.8 \%$ over the previous year. However, compared with the bank loan balance of 155.72 trillion yuan at the end of 2018, the scale of credit asset securitization is still small. As of April 2019, only 18 of the 560 existing credit asset securitization products were issued by rural financial institutions, and all the issuers were rural commercial banks (Note 1). Among the 11 credit asset securitization products, from the perspective of scale, the average size of each is 1.329 billion yuan. Except for the "Pearl River 2017 First Phase Credit Asset-Backed Securities" issued by Guangzhou Rural Commercial Bank, which has a scale of 6 billion, the scale of other products is less than 2 billion yuan, which is far smaller than the scale of asset securitization products issued by other types of commercial banks.

\subsection{Characteristics of Rural Banks and Issuance Constraints}

Compared with general commercial banks, Rural banks have the characteristics of fixed operating objects, high credit and liquidity risks, and small capital scale. First, the customers that Rural Banks face are mainly farmers and small and micro enterprises. As of the third quarter of 2019, the balance of various loans of rural financial institutions nationwide was 15.37 trillion yuan, of which single loans were less than 10 million yuan small and micro enterprise loan scale is 423 million yuan. Among them, small- and micro-enterprise loans with a single size below 10 million yuan totaled 423 million yuan. The customer structure determines that the credit risk of bank loans to villages and towns is high and the ratio of repayment on time is low. In the first three quarters of 2019, the non-performing loan ratio of rural financial institutions in China was $4.00 \%$, which was much higher than the average level of other types of commercial banks at $1.45 \%$. Second, the deposits and loans of rural banks are relatively high. In 2018, the balance of various deposits of rural banks nationwide was 949.29 billion yuan, and the balance of various loans was 702.06 billion yuan, and the loan-to-deposit ratio was $73.95 \%$, which was higher than the average level of $69.4 \%$ for commercial banks, and the asset liquidity was poor. Third, in order to pursue liquidity and meet the needs of cyclical production in rural areas, the rural banks have a small loan amount, of which the loan amount of less than 5 million yuan accounts for about $80 \%$. The income from a single credit business is also small, and the rural banks with poor profitability are more inclined to issue asset securitization products.

However, due to the above characteristics of rural banks, the implementation of asset securitization will face many problems. First, the operating targets of rural banks are mainly rural residents and small and micro enterprises. Due to the seasonal factors of agricultural production, loans are mostly short-term, with large liquidity and unstable asset pools, which is not conducive to building a stable asset pool for issuing bonds. Secondly, the single credit limit of rural banks is low. If a single small bond issuance during asset securitization, it is difficult to attract buyers, and investors also lack trust in small-scale asset securitization products. Third, in the process of asset securitization of rural banks, high rating fees have become a major threshold. China's rating system is not complete, and external trust is insufficient. Third, in the process of asset securitization of rural banks, high rating fees have become a big threshold. The current rating system in China is not complete, and external trust is insufficient. 


\subsection{Feasibility Analysis of Joint Issuance of Asset Securitization Products by Rural Banks}

Asset securitization can revitalize the assets of rural banks and effectively improve operating income. It is a good way to solve the current operating difficulties of rural banks in China. However, the average size of credit asset securitization products in the Chinese market is about 4 billion. The scale of credit is much smaller than that of general asset securitization products, and a single entity's issuance faces many constraints. If multiple rural banks jointly issue credit asset securitization products, first, it can solve the problem of the small size of a single bank's assets, so that the quality assets of multiple banks can be integrated to build a stable asset pool to achieve the scale of general asset securitization products. Second, it can solve the problems caused by the short term and small amount of single loans of rural banks. It is easier to select multiple similar loans in the asset pools of multiple banks to form a bond, and bonds of a certain size can better attract investors. Thirdly, the issuance of asset securitization products by multiple banks can amortize costs and risks. The rating and operating expenses borne by many rural banks will be reduced, which is more suitable for the operation background of rural banks. In the United States, there is already experience in community bank joint issuance of asset securitization products. In 2017, 25 banks with assets ranging from US \$200 million to US \$1 billion jointly issued a US \$155 million non-performing loan asset securitization product. As China's rural banks are similar in size, business objects, and characteristics of credit assets to community banks in the United States, China's rural banks can learn from the experience of joint issuance of asset securitization products by multiple community banks in the United States.

\section{Implementation Path}

As a low-cost financing method, asset securitization can effectively improve the capital adequacy ratio of commercial banks, enhance profitability, and improve capital utilization efficiency (Haifeng \& Shijin, 2017). China's large commercial banks have many years of experience in developing credit asset securitization. However, the credit assets of rural banks are low and short-term. They have the characteristics of liquidity risk and high credit risk. Rural banks and other commercial banks have different business objects, scales, and risk tolerance, and credit assets are generally small and short in time. Therefore, the model of asset securitization of large commercial banks is not applicable, it is necessary to carry out targeted design for asset securitization products issued by rural banks. Rural banks are smaller in scale than large commercial banks and city banks, and it is more difficult for a single rural bank to issue asset securitization products. Asset securitization mainly includes the steps of determining assets and forming asset pools, designing transaction structures, credit enhancement, credit ratings, selling securities, and managing asset pools. Among them, the three cores in the design of asset securitization products are the establishment of asset pools, the design of transaction structures, and credit enhancement. Referring to the existing successful practice of asset securitization of foreign community banks, this paper intends to use the joint issue of five rural banks to discuss the three main aspects of the construction of the asset pool, the design of the transaction structure, and the means of credit enhancement. The idea of implementing asset securitization in rural banks (Note 2).

\subsection{Construction of Asset Pool}

As the initiator of asset securitization, a rural bank is an important prerequisite for the smooth development of asset securitization business. First, due to the short term of the credit business of rural banks and the small amount of single credits, the construction of asset pools has become a difficult problem. Therefore, to allocate the assets to the pool reasonably, select five rural banks that have basically the same maturity to enter the pool. Guarantee the stability of the asset pool within limits. Secondly, the credit risk of rural banks is relatively high. In the latest rating of the central bank, 420 rural banks among the high-risk banks of grades 8 to 10 have reached 109 (Financial Stability Analysis Group of the People's Bank of China, 2018). Since most of the loans to rural banks are farmers, the overdue rate is relatively high (Lushi et al., 2012), so the risk level of assets should be rigorously screened when constructing an asset pool. Third, when multiple rural banks jointly issue asset securitization products, in order to avoid large differences in economic development in different regions and different regulatory policies, in order to facilitate practical operations, it is necessary to find rural banks within the same region when joint issuance of products.

\subsection{Design of Transaction Structure}

In the process of asset securitization, the method of real sales is generally used to issue asset securitization products by selling the ownership of assets to special purpose institutions (SPVs). However, under the scale of the existing rural banks, the issue of credit asset securitization products by a single rural bank will cause its own capital adequacy ratio and deposit-loan ratio to be difficult to fulfill regulatory requirements. Therefore, the joint issue of multiple rural banks is more feasible. Select five banks to meet the requirements for credit assets into the 
pool; in terms of purchase structure, due to the cyclical nature of agricultural production and the short-term financing of small and micro enterprises, concentrated within 12 months, and the issued asset-backed securities generally have a longer term, Therefore, there will be a term mismatch. Therefore, the method of circularly purchasing the assets in the pool is used to keep the size of the assets stable, and at the same time, the efficiency of fund use can be improved; the action of selecting the underlying assets is performed by the SPV manager. The income generated during the life of the product should be used to pay the interest on the priority bonds first. The remaining part is used to purchase new eligible assets after deducting various expenses, so that the asset pool is continuously replenished to maintain a stable scale. If the loan size of the asset pool in the process is less than the issue amount, the manager can purchase assets from the alternative asset pool that meet the requirements and supplement the issue amount of the asset-backed securities. Bank A sells the ownership of the assets to the trust company as the sponsor. The issued bonds adopt a priority / subordinate structure, and the credit rating agencies will rate the bonds, and the proportion of subordinated bonds will be controlled within $13.8 \%$ (Note 3 ).

\subsection{Credit Enhancement}

In the process of issuing asset-backed securities, in order to improve the credit rating agency's rating on bonds, it is necessary to raise the credit rating of asset-backed securities. For investors, due to the consideration of risks and returns, institutional investors have certain restrictions on their investment, and individual investors also tend to choose products with determined returns. In order to meet the needs of investors and reduce the credit risk of asset-backed securities, credit enhancement can effectively isolate the product from the operating risks and credit risks of the rural banking business. There are two main types of credit enhancement: internal and external.

\subsubsection{Internal Step-Up Measures}

First, the priority / substructure. In the distribution process of the future cash flow of the product, according to the order of repayment, priority bonds are paid first, and subordinated bonds are paid later. When no default event occurs, the priority bonds should pay the principal and interest before the subordinated bonds. When a default event occurs, the subordinated bonds should bear the risk for the priority securities. This measure allows rural banks not to be constrained by their own asset scale, but also to combine high-quality and stable assets to issue higher-level securities.

Second, excess reserves. In the process of constructing the asset pool, the initiator of the asset securitization product should establish an asset pool with a total value higher than the total value of the actual securities issued in the alternative assets. Under normal circumstances, the excess value is sufficient to support the repayment of the principal and interest of the product, and it can provide loss provisions when losses occur. This measure is relatively easy to operate, relatively low cost and highly feasible for the relatively fragmented loans of rural banks.

Third, the cash reserve account. This is to set up an account by the promoter and deposit a certain amount of cash. When the risk occurs, the principal and interest will be repaid in a timely manner to avoid default. The term of rural bank loans is generally short, and recurrent transactions will occur during the life of the product. This measure can effectively avoid defaults caused by cyclic interruptions.

\subsubsection{External Step-Up Measures}

First, external guarantees and insurance. It is a common credit enhancement method for third-party institutions to provide guarantees for bonds issued to guarantee the smooth repayment of principal and interest, and it is also applicable to rural banks. The originating bank of a rural bank is generally a large commercial bank with a high level of creditworthiness and can be used as the main guarantee agency for asset securitization products.

Second, standby letters of credit. A standby letter of credit is a type of guarantee letter of credit issued by a third-party financial institution to guarantee the smooth repayment of the principal and interest of a secured claim. Generally, in the event of a default, a third party will purchase this part of the bond at the agreed price to reduce losses. For rural banks, this method can make the credit level of asset-backed securities independent of the rural bank's credit level, and it is more convenient to operate when multiple banks face risks.

Third, cash mortgage accounts. Different from the first two credit enhancement methods, the cash mortgage account is not affected by the credit ratings of the issuer and the asset-backed securities product itself, but instead uses the income obtained from the additional capital investment to make up for possible losses. This method strengthens the credit base of the product. Although it may take a larger amount of funds in order to pursue considerable profits, the cost sharing of multiple banks makes this method very feasible.

Taking the above credit enhancement method can effectively improve the credit rating of bonds and reduce the losses caused by defaults, but defaults are still inevitable. Different from asset-backed securities issued by one 
bank as the sponsor, multiple banks jointly issue products to share benefits and bear risks.

\section{Example Analysis}

\subsection{Construction of Asset Pool}

The asset securitization scheme designed in this article relies mainly on the loan products of rural banks, so the single amount $S_{k}$, interest rate level $i_{k}$, term $n_{k}$, credit risk $R_{k}$ and other factors selected for the pooled assets need to be evaluated $(k=1,2,3,4,5$; represents banks A, B, C, D, E) (Note 4).

Assume the following factors for the assessment of assets entering the pool:

The interest rate of the loan $i_{k}$. Since the operating environment of rural banks is similar to that of customers, the loan interest rates of the banks are not significantly different. Calculate the weighted average loan interest rate $i_{k}$ of all loans of each bank under the interest rate requirements. In order to ensure the stability of the asset pool, the pooled assets are selected to fluctuate by $1 \%$ above and below $i_{k}$, which can ensure that the future returns of asset-backed securities are even.

The term of the loan $n_{k}$. Rural bank loans have the characteristics of short term. In order to facilitate the combination of assets into the pool and to ensure the stability of the asset pool, the selected loan period needs to be matched with the production cycle of farmers and the characteristics of financing needs of small and micro enterprises to make cyclical purchases.

Credit risk of the loan $R_{k}$. When selecting this part of the asset, lenders who have previously defaulted and overdue should be excluded, and normal loans should be taken into the pool to minimize credit risk.

Single amount $S_{k}$. In order to avoid the instability of the asset pool caused by the small and short-term characteristics of loans of rural banks, a portion of which is between 500,000 and 5 million yuan is selected for pooling.

In order to maintain the stability and liquidity of the asset pool and minimize the risk, the selected assets should meet the following pool entry criteria: the weighted average loan interest rate of the selected five banks is $8.02 \%$, and the interest rate of the assets entered in the pool is selected at $7.02 \%$ to $9.02 \%$, which can ensure that future interest income is more even, and loans that meet this standard account for $75 \%$ of the total. Choose a loan of 500,000 to 5 million in the amount of loans to facilitate the subsequent management of assets in the pool; all assets in the pool should be considered for normal loans to minimize the risk of default; the amount of five banks that meet the above criteria has reached 2,399.94 million yuan. In order to cooperate with credit enhancement measures, only $80 \%$ of the assets in the asset pool that meet the above conditions were purchased for the first time, and the remaining part was used as excess reserves to facilitate circular purchases and timely replenishment of losses. The total size of the credit-backed securities totaled 1919.59 million. The indicators of the credit assets of the five banks are as follows (Note 5).

Table 1. Basic situation of credit asset indicators

\begin{tabular}{cccccc}
\hline Bank name & $\mathrm{A}$ & $\mathrm{B}$ & $\mathrm{C}$ & $\mathrm{D}$ & $\mathrm{E}$ \\
\hline Total loan (1 million yuan) & 1250 & 650 & 482 & 400 & 520 \\
Weighted average interest rate & $7.86 \%$ & $8.02 \%$ & $7.95 \%$ & $8.11 \%$ & $8.15 \%$ \\
Normal loan ratio & $96.90 \%$ & $96.60 \%$ & $97.10 \%$ & $97.20 \%$ & $96.80 \%$ \\
Amount of normal loans (1 million yuan) & 1211.25 & 627.9 & 468.02 & 388.8 & 503.36 \\
\cline { 2 - 6 } & \multicolumn{5}{c}{ Loan amount (1 million yuan) } \\
\cline { 2 - 6 } $0.1 \sim 0.5$ million & 112.5 & 58.5 & 43.38 & 36 & 46.8 \\
0.5-5 million & 975 & 507 & 375.96 & 312 & 405.6 \\
5 million yuan or more & 162.5 & 84.5 & 62.66 & 52 & 67.6 \\
\hline
\end{tabular}

\subsection{Monte Carlo Simulation-Based Asset-Backed Securities Pricing}

Monte Carlo simulation is a common method of pricing asset-backed securities. This method is based on the value of assets, and through simulation of various interest rates that may exist in the future, the present value of the asset portfolio of asset-backed securities under different simulation times is obtained.

The first step is to determine the cash inflow of the asset pool. As the rural bank loan business is generally short in time and small in amount, the volatility of the asset pool is not sharp. We use the discounted cash flow method to determine the cash flow of asset-backed securities in the next two years. Asset securitization products are 
repaid on a monthly principal and interest basis and are divided into 24 periods. Since the average term of a single loan from a rural bank is approximately 6 months, the asset pool is classified at half-year intervals. Assume that the maturity distribution of the underlying asset pool is shown in Table 2.

Table 2. Remaining maturity and principal balance of the basic asset pool

\begin{tabular}{ccccc}
\hline $\begin{array}{c}\text { Remaining } \\
\text { period }\end{array}$ & $\begin{array}{c}\text { Number of } \\
\text { contracts }\end{array}$ & $\begin{array}{c}\text { Principal balance } \\
\text { (ten thousand yuan) }\end{array}$ & Proportion & $\begin{array}{c}\text { Average single balance } \\
\text { (ten thousand yuan) }\end{array}$ \\
\hline $1 \sim 6$ months & 318 & 55668.38 & $29 \%$ & 175.06 \\
$7 \sim 12$ months & 289 & 59507.58 & $31 \%$ & 205.91 \\
$13 \sim 18$ months & 194 & 42231.18 & $22 \%$ & 217.69 \\
$19 \sim 24$ months & 121 & 34552.79 & $18 \%$ & 285.56 \\
\hline Total & 922 & 191959.92 & $100 \%$ & 884.21 \\
\hline
\end{tabular}

The asset pool interest rate rises by $60 \%$ according to the central bank's current benchmark interest rate (Note 6). There are no prepayments and defaults for assets in the pool, and the cash flow in each period is smoothly distributed. The resulting cash flow budget for the asset portfolio is shown in Table 3.

Table 3. Budget flow of asset pools (Unit: ten thousand yuan)

\begin{tabular}{cccc}
\hline Period & Principal inflow & Principal inflow & Total inflows \\
\hline 1 & 8828.66 & 753.36 & 9582.02 \\
2 & 8301.68 & 708.39 & 9010.07 \\
3 & 8670.71 & 739.88 & 9410.59 \\
4 & 8319.87 & 709.94 & 9029.81 \\
5 & 8179.38 & 697.96 & 8877.34 \\
6 & 8360.66 & 713.42 & 9074.08 \\
7 & 8466.5 & 722.46 & 9188.96 \\
8 & 7803.22 & 665.86 & 8469.08 \\
9 & 8381.24 & 715.18 & 9096.42 \\
10 & 7389.83 & 630.58 & 8020.41 \\
11 & 8627.1 & 736.16 & 9363.26 \\
12 & 7988.76 & 681.69 & 8670.45 \\
13 & 8023.88 & 684.69 & 8708.57 \\
14 & 8503.51 & 725.61 & 9229.12 \\
15 & 8423.92 & 718.82 & 9142.74 \\
16 & 7529.55 & 642.5 & 8172.05 \\
17 & 8031.17 & 685.31 & 8716.48 \\
18 & 8269.46 & 705.64 & 8975.1 \\
19 & 6854.59 & 584.91 & 7439.5 \\
20 & 8085.48 & 689.94 & 8775.42 \\
21 & 7297.16 & 622.67 & 7919.83 \\
22 & 6998.8 & 597.21 & 7596.01 \\
23 & 6763.43 & 577.13 & 7340.56 \\
24 & 7861.36 & 670.82 & 8532.18 \\
\hline Total & 191959.92 & 16380.13 & 208340.06 \\
\hline
\end{tabular}

The second step is to determine the expected interest rate. The future cash flow of the asset is the inflow of accounts receivable in period $\mathrm{t}$, which is recorded as $C F_{t}$. Since it is an estimate of future cash flow, $C F_{t}$ cannot be discounted directly. Instead, mathematical statistical methods should be used to predict the future interest rate trend based on the past risk-free rate interest rate. An expected future cash flow plus an expectation is $E\left(C F_{t}\right)$. To determine the future expected cash flow, we must first determine the discount factor. Generally, the discount rate is affected by three factors: time value of money, inflation, and risk compensation. The macroeconomic situation is closely related and it is difficult to estimate. The time value of money is affected by interest rate expectations, and the term structure of interest rates plays an important role in forecasting future interest rates (Hongjin, 2012). 
We selected the CIR (Cox-Ingersoll and Ross) interest rate term structure model to estimate interest rate expectations. Cox, Ingersoll, and Ross (1985) proposed a CIR model in the study of the term structure of interest rates. Its differential expression is:

$$
d r=\alpha(R-r(t)) d t+\sigma \sqrt{ } r d w
$$

Where $\mathrm{dr}$ is the change in interest rate, $\mathrm{r}(\mathrm{t})$ is the short-term interest rate in period $\mathrm{t}$, the long-term level of $\mathrm{R}$ interest rate, $\alpha$ is the regression speed of $r(t)$ around $R$, and it has a mean regression characteristic, $\sigma$ is the volatility of $\mathrm{r}(\mathrm{t})$, and $\mathrm{dw}$ is a random term in the model. It follows a normal distribution with mean 0 and variance dt. The CIR model believes that interest rates fluctuate around an average value and are non-negative. The volatility of interest rates is positively correlated with interest rate levels, that is, the higher the interest rate level, the greater the volatility.

Table 4. Present value of cash flow in each period (Unit: ten thousand yuan)

\begin{tabular}{cccc}
\hline Period & 500 simulation averages & 1000 simulation averages & 2000 simulation averages \\
\hline 1 & 9259.25 & 9557.55 & 9557.7 \\
2 & 9146.45 & 8961.6 & 8962.15 \\
3 & 9129.2 & 9331.35 & 9331.75 \\
4 & 8836.6 & 8925.3 & 8927.7 \\
5 & 8830.6 & 8745.65 & 8747.75 \\
6 & 8952.3 & 8908.65 & 8909.9 \\
7 & 8626.6 & 8987.2 & 8992.2 \\
8 & 8549.1 & 8256.35 & 8257.5 \\
9 & 8299.9 & 8833.3 & 8842.1 \\
10 & 8400.95 & 7756.3 & 7770.2 \\
11 & 8684.75 & 9019.55 & 9029.35 \\
12 & 8342.55 & 8323.45 & 8332.2 \\
13 & 8579.45 & 8331.3 & 8333.45 \\
14 & 8750.55 & 8797.2 & 8800.95 \\
15 & 8219.2 & 8682.4 & 8684.9 \\
16 & 7989.55 & 7731.4 & 7732.55 \\
17 & 8345.05 & 8215.8 & 8224.2 \\
18 & 7721.1 & 8430.7 & 8441.7 \\
19 & 7594.05 & 6964.6 & 6971.2 \\
20 & 7785.3 & 8185.35 & 8199.7 \\
21 & 7205.3 & 7361.65 & 7374.45 \\
22 & 6908.7 & 7029 & 7050.35 \\
23 & 7298.15 & 6768.55 & 6781.65 \\
24 & 104010.95 & 7838.1 & 7844.5 \\
\hline Total & 200050 & 199940 & 200100 \\
\hline
\end{tabular}

To determine the expected interest rate, the parameters $\alpha, R$, and $\sigma$ in the CIR model need to be estimated. Overnight repo rates are commonly used internationally as risk-free rates. In China, short-term government bond rates, SHIBOR rates, and inter-bank pledge rates have been proposed as risk-free rates. The 3-month SHIBOR rate is similar to international market standards (Guanghui \& Chengyue, 2015). We use 3,055 SHIBOR March interest rates from October 6, 2006 to December 31, 2018 as the benchmark interest rate to predict future interest rate changes. First, use the ordinary least square method to estimate the initial values of the parameters. The maximum likelihood function estimation method is more accurate (Wei \& Yunlin, 2012). The initial value was substituted into MATLAB program for calculation. The parameters under the maximum likelihood estimation are $\alpha=1.1243, \mathrm{R}=4.3895, \sigma=0.9632$. The initial value is $\mathrm{r} 0=3.069$. Expected interest rate is:

$$
d r=1.1243(4.3895-r(t)) d t+0.9632 \sqrt{ } r d w
$$

The third step is to convert the cash flow of each period. The theoretical price of additional asset-backed securities is $\mathrm{P}=\mathrm{E}\left[\int_{1}^{n} C F(t) d t\right.$. The discount factor can be obtained from the CIR model. Run the MATLAB program, use the Monte Carlo method to perform 500, 1000, and 2000 simulations of cash flow, and average the discounted cash flow for each period in the three cases. 
The present value of the asset-backed securities product simulated by the Monte Carlo method 1000 times was 199.4 million yuan, and the errors with the 500 and 2000 simulations were less than $0.1 \%$. Therefore, this paper uses the sum of cash flows in each period under 1000 simulations as the present value of the asset portfolio. Although multiple credit enhancement measures have been taken, products in the asset pool may still default, assuming a default rate of $1 \%$. In addition, the process of issuing asset-backed securities involves a number of management costs, assuming $2 \%$.

It was finally determined that the five asset-backed securities of the five rural banks planned to issue about 1.920 billion yuan, of which 1.663 billion yuan were senior bonds and 257 million were subordinated bonds. The project scale of general asset-backed securities has been reached. The Monte-Carlo simulation of the asset-backed securities project's issuance pricing is approximately 193.94million, which is slightly higher than the proposed amount. If the risk of prepayment and the uncertainty of future risks are considered, the pricing of asset-backed securities projects will be basically close to the issue amount, indicating that this scheme is operational.

\section{Conclusion}

The implementation of credit asset securitization business by rural banks has great benefits in revitalizing assets, improving liquidity, and reducing credit risk. Rural banks have similar operating backgrounds, loan targets, and loan durations. This paper has designed a number of rural banks to jointly issue asset-backed securities products. By screening factors such as the size, maturity time and credit level of credit assets of various banks, the combination of high-quality assets entered the asset pool. Using Monte Carlo simulation method, it is found that the present value of the asset pool is very close to the issue scale, and the scheme is operable. The joint issuance of asset-backed securities products by multiple rural banks can not only solve the problem of the instability of the asset pool caused by the small asset size of a single rural bank, but also reduce the credit risk and share rating costs of a single bank. The joint issue scheme is feasible. In the actual issuance process, considering the complex default and early repayment risks, how each bank shares the risks deserves further discussion.

\section{References}

Financial Stability Analysis Group of the People's Bank of China. (2018). China Financial Stability Report 2018. Beijing: China Finance Press.

Guanghui, H., \& Chengyue, Y. (2015). Research on Interest Rate Structure, Information Spillover and Formation Mechanism of China's Interbank Market. The Journal of Quantitative \& Technical Economics, (11), 3-22.

Haifeng, H., \& Shijin, C. (2014). Innovative financing model to resolve the dilemma of new urbanization financing. Economic Developments, (07), 57-59.

Hongjin, L. (2012). Long-term interest rate forecasting function of the term structure of interest rates — - Testing the expectation hypothesis modified by term premium. Journal of Financial Research, (08), 97-110.

Jianguo, M., Xinyang , G., \& Yan, Y. (2018). Research on the Feasibility and Pricing of Rural Household Loan Asset Securitization. Journal of Management Sciences, (05), 81-89. https://doi.org/10.3969/j.issn.1007-9807.2018.05.006.

Lei, Z., \& Lina, W. (2015). Practice and Thoughts on Credit Asset Securitization of Rural Financial Institutions. Financial Perspectives Journal, (03), 71-74.

Lushi, Y., Xuan, W., \& Xiao, N. (2012). An Empirical Study on the Securitization Effect of Bank Credit Assets__Based on Panel Data of the US Banking Industry. Studies of International Finance, (09), 71-78.

Wei, G., \& Yunlin, S. (2012). Parameter Estimation for a Class of Diffusion Process and Its MATLAB Implementation. Statistics \& Decision, (19), 102-104.

Xiaomei, Z., Ming, Z., \& Pei, G. (2015). Asset securitization and commercial bank profitability: Correlation, impact path and crisis shock. Global Economy, (11), 144-167.

Xiaoxian, C., \& Duruo, L. (2017). Research on the Micro-motives of Credit Asset Securitization-An Empirical Analysis Based on the Data of China Commercial Bank. Journal of Shanxi University of Finance and Economics, (02), 22-34.

Zhaowei, H., \& Rihong, Z. (2013). Rural Household Securitization: Structural Design and Credit Enhancement. Financial Theory and Practice, (07), 62-65. https://doi.org/10.3969/j.issn.1003-4625.2013.07.013 


\section{Notes}

Note 1. Source: wind.

Note 2. As of April 2019, the average size of credit asset securitization products was 4.779 billion yuan, of which the average size of consumer credit was 2.328 billion yuan. Considering that consumer credit and rural bank loans also have the characteristics of small single-size and short-term, Therefore, the regulation simulation of asset securitization products of rural banks is set at about 2 billion yuan

Note 3. As of April 2019, the average subordinated proportion of 566 credit business asset-backed securities projects.

Note 4. Five rural banks in Jiangsu Province, China.

Note 5. The total loan amount, weighted average loan interest rate, loan quota distribution, and loan maturity distribution are revised with reference to the loan business data of 76 rural banks in Jiangsu Province, and the normal loan ratio is revised with reference to the Jiangsu Banking Regulatory Commission statistics.

Note 6. The one-year (including) loan interest rate announced by the People's Bank of China in 2018 was $4.35 \%$, and the one- to three-year (including) loan interest rate was $4.75 \%$. The loan interest rate within one year of the asset pool will rise by $60 \%$ at $4.35 \%$, and the interest rate of loans above one year will rise at $60 \%$ at $4.75 \%$.

\section{Copyrights}

Copyright for this article is retained by the author(s), with first publication rights granted to the journal.

This is an open-access article distributed under the terms and conditions of the Creative Commons Attribution license (http://creativecommons.org/licenses/by/4.0/). 